$5^{\text {th }}$ International Conference on Innovation in Science and Technology

Barcelona - Spain

\title{
ISTCONF
}

7 - 9 December, 2018

\section{MEMBRANE ELECTRO-BIOREACTOR (MEBR) ACHIEVES HIGH NITRIFICATION RATES}

\section{Abdelmajeed Adam \& Maria Elektorowicz}

Department of Building Civil \& Environmental Engineering (BCEE), Concordia University,

\begin{abstract}
The performance of any nitrifying wastewater treatment processes are closely linked to the microbial community structure and dynamics. In this work, the effects of low-intermittent DC electrical filed on the change of nitrifying community structure and process performance were examined. Microbial populations and dynamics were characterized using fluorescent in situ hybridization (FISH) techinque. The results demonstrated that submerged membrane electrobioreactor (SMEBR) system achieved substantial nitrification rates comparing to conventional MBR system. FISH analysis indicated a dominance of different nitrifiering bacteria in both reactors, which could be a reason for the variation in nitrification performance. In SMEBR system, rapid nitrifiers such as AOB (Nitrosomonas spp.) and NOB (Nitrobacter spp.) were dominated. In contrast, control MBR was occupied by slower nitrifiers groups like AOB (Nitrosospira spp.) and NOB (Nitrospira $s p p$.). Such findings are of importance to design more effective nitrifying-based process, while more cost-saving opportunities are offered.
\end{abstract}

Keywords: nitrogen removal; nitrification rate; nitrifiers community; submerged membrane electro-bioreactor (SMEBR) system; sustainable design 